\title{
New measurement methods and devices and evaluation framework for characterizing of hydrological properties of growing media
}

\begin{abstract}
Background: Hydraulic properties of horticultural substrates are important variables for a comprehensive evaluation of its performance for horticultural application. The commonly used measurement and evaluation methods and devices are outdated.

Objective: 1. Test of new measurement methods and devices (EEM, HYPROP) for quantifying the water and air capacity, the hydraulic conductivity, the shrinkage and rewetting. 2. Development of a rating framework to assess the hydraulic suitability of substrates used in horticulture.

Materials and methods: The hydraulic properties of 36 commercial horticultural substrates were quantified and evaluated.

Results: EEM and HYPROP enable the simultaneous and effective measurement of the water retention curve and the unsaturated hydraulic functions. Furthermore, the shrinkage properties and the water rewetting time were measured. A rating framework for evaluating the hydraulic quality of horticultural substrates was developed and successfully tested within a comparison of 36 commercial horticultural substrates.

Conclusion: The applied methods proved to be suitable. The hydraulic performance of totally peat-free substrates was not worse than those containing peat. The most sensitive element of horticultural substrates was the air supply, especially for cultivation in shallow containers. The proposed evaluation framework provides an opportunity to compare the hydraulic properties of different composed substrates.

Keywords: horticultural substrates, growing media, hydraulic quality, rating framework, water retention curve, unsaturated hydraulic conductivity, water repellency, water drop penetration time, shrinkage, extended evaporation method (EEM), HYPROP
\end{abstract}

Abbreviations: CR, capillary rise; EAW, easy plant available water; EEM, extended Evaporation Method; H, peat decomposition; hPa, hecto Pascal; HS: horticultural substrate; HYPROP, Hydraulic Property Analyzer; Ls3, sandy loam; Lts, clayey loam, WDPT, Water Drop Penetration Time Method

\section{Introduction}

Horticultural substrates are special designed media for horticultural applications. Bog peat is the main basis for creating horticultural substrates (Other ingredients like coir, perlite, compost and other are added to improve the substrate for special horticultural applications. ${ }^{1-3}$ Beside the nutrient composition, the hydraulic performance of horticultural substrates is a main issue for evaluating its quality for horticultural purposes. However, information to the hydraulic properties is missing of the substrate package. Until recently substrate buyers cannot draw any conclusions regarding the hydraulic properties on the basis of the declaration and the ingredients of the particular product he has bought,,$^{1,3-5}$ concluded that there is a lack of technologies and methods for the effective physical characterization and evaluation of substrate application in horticulture. The papers ${ }^{3-5}$ are in the public domain.

\section{Aim of the study}

1. The suitability of the extended evaporation method $\mathrm{EEM}^{6}$ and the associated HYPROP for quantifying the water retention curve and the hydraulic conductivity function should be tested for the
Volume 2 Issue 4 - 2018

\author{
Uwe Schindler, ${ }^{2,3}$ Lothar Mueller, ${ }^{3}$ Frank \\ Eulenstein ${ }^{1,2,3}$ \\ 'Leibniz Centre for Agricultural Landscape Research (ZALF), \\ Germany \\ 2Mitscherlich Academy for Soil Fertility (MITAK), Germany \\ ${ }^{3}$ Kuban State Agrarian University, Russia
}

\begin{abstract}
Correspondence: Uwe Schindler, Mitscherlich Academy for SoilFertility, Proffessor Mitscherlich Allee, I, I464I Paulinenaue, Germany,Tel +49 I52 53560493, Email schindler@mitak.de
\end{abstract}

Received: December 06, 2017 | Published: July 27, 2018 very loosely bedded horticultural substrates. Furthermore, the HYPROP should be used for measuring the shrinkage behaviour and the Water Drop Penetration Time Method (WDPT, ${ }^{7}$ should be tested for quantifying the rewetting properties of the horticultural substrates.

2. Development of a rating framework to assess the hydraulic suitability of substrates used in horticulture.

3. Measurement, comparison and evaluation of the hydraulic properties and quality of 36 commercially available substrates for horticultural applications(Figure 1).

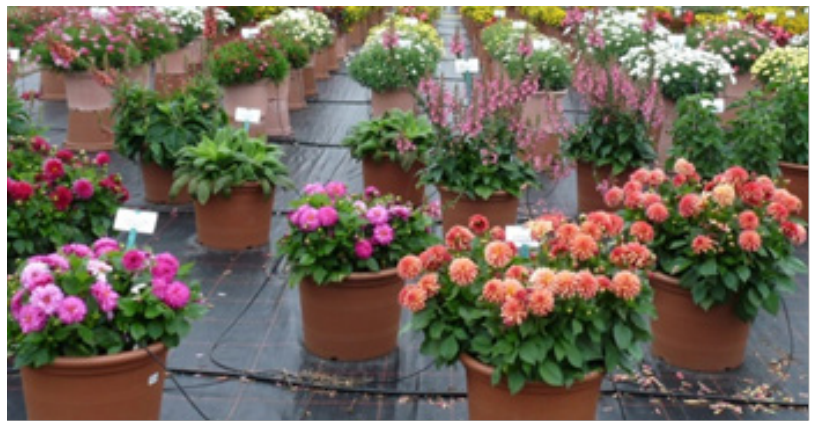

Figure I Growing media like peat, compost or other substrates are needed for horticulture and landscaping. 


\section{Materials and methods}

The suitability of the EEM and the HYPROP was tested at 18 commercial horticultural substrates and comparatively at 10 mineral and organic soils. A similar method has been used in previous studies. ${ }^{4}$ One of the horticultural substrates was totally free of bog peat. The natural fen soil material was collected from the "Roten Luch" area close to Muencheberg, Brandenburg, Germany. Sampling depth was $80 \mathrm{~cm}$. The degree of decomposition ${ }^{8}$ was determined with H7. The comparison and evaluation of the hydraulic suitability was carried out at further 36 horticultural substrates.

Sample preparation: A plastic pipe (diameter $15 \mathrm{~cm}$ and height $65 \mathrm{~cm}$ ) was loosely filled with the substrate up to $5 \mathrm{~cm}$ underneath the upper edge. Water was added at the surface as long as water left at the bottom of the pipe. The pipe was placed for 2days in a pan with a $3 \mathrm{~cm}$ water level. The substrate compacted itself hydraulically and after 2 days the capillary equilibrium was reached. At this time, the tension at the surface layer was about $50 \mathrm{hPa}$. The substrate material of the upper $5 \mathrm{~cm}$ layer of the pipe was taken, mixed and loosely filled into the $250 \mathrm{~cm}^{3}$ HYPROP steel cylinders. During the filling procedure the cylinder was stamped ten times. The thus prepared sample was saturated and ready for the hydraulic measurements with HYPROP. This procedure is derived from ${ }^{9}$ and ${ }^{10}$ and guarantees a high reproducibility. It enables the hydraulic comparability of growing media with different basic moisture of the substrates in the package.

\section{Hydraulic criteria}

The most important aspects are

(i) The amount of easily plant-available water (EAW).

(ii) The air capacity depending on the kind of cultivation. The capillary rise is an additional indicator for characterizing the transport properties.

(iii) The rewetting time.

(iv) The shrinkage dynamics could negative influence the hydraulic substrate quality.

\section{Measurement of the water retention curve and the unsaturated hydraulic conductivity function}

The EEM enables the simultaneous measurement of the water retention curve and the hydraulic conductivity function. Using new cavitation tensiometers and applying the air entry value of the tensiometer's ceramic cup, it allows the range to be extended almost up to the wilting point. The measurements were carried out using the HYPROP system. HYPROP ${ }^{11}$ is the commercial device to implement the EEM. The total measurement time depends on the soil or substrate and the evaporation conditions and ranged between 3 and 10days. Multiple samples can be measured simultaneously(Figure 2).
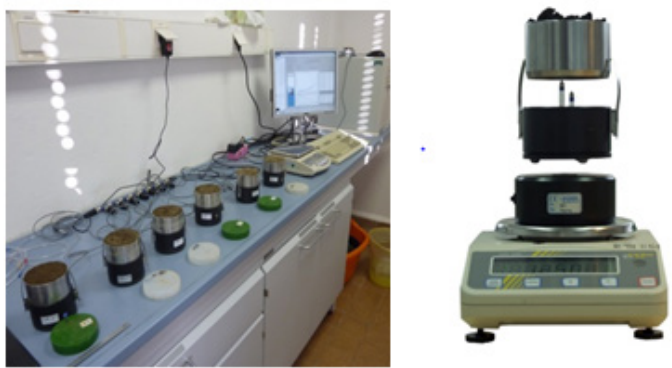

Figure 2 HYPROP for measuring the hydraulic properties.

\section{Rewetting properties}

The Water Drop Penetration Time Method ${ }^{7}$ was used in this study for quantifying the rewetting properties. The method is based on the time taken for a drop of water to infiltrate into the substrate. Using a pipette, one drop of water was added to the sample and the water penetration time was measured. The measurement was executed at different times during the evaporation experiment to get WDPT values at tensions of approximately $100 \mathrm{hPa}$. The measurement was repeated 3 times for calculating the average value. This procedure is easy to handle and does not need a great deal of technical effort.

\section{Shrinkage measurement}

The shrinkage was estimated during the evaporation experiment. The diameter of the sample's surface was measured at a tension of about $100 \mathrm{hPa}$ using a calliper. The shrinkage from the bottom to the top of the sample is linear in this tension range. ${ }^{12}$ Concluding, the shrinkage of the sample can be calculated (Eq. 2). Isotropic conditions are assumed.

$$
V_{s}=\frac{\pi}{4} *\left[\frac{d_{i}+d_{s}}{2}\right]^{2} * h_{s}
$$

where: $V_{s}$ is the volume of the shrunken sample, $d_{i}$ is the initial sample diameter, $d_{s}$ is the diameter at the sample's surface at $100 \mathrm{hPa}$, $\mathrm{h}_{\mathrm{s}}$ is the height of the shrunken sample. A more accurate but also more complicated method is described by. ${ }^{12}$ Here the shrinkage is measured online during the evaporation process.

\section{Results and discussion}

The HYPROP proved to be suitable for measuring the hydraulic properties also of the very loosely bedded horticultural substrates. Same conclusion was drawn by. ${ }^{13}$ Furthermore, ${ }^{13}$ showed also the good agreement of water retention functions obtained with the HYPROP with those measured with the standard pressure plate apparatus. These findings agree well for water retention functions of mineral and organic soils ${ }^{14,15}$ and the unsaturated hydraulic conductivity measured with the HYPROP and the multi-step-outflow-method. ${ }^{16}$ The results obtained in this study agree with previous studies ${ }^{4,5}$ and confirm findings presented in ${ }^{13}$ the water retention curves of all tested natural mineral and organic soils and exemplarily of three horticultural substrates are illustrated in Figure 3. The easily plant available water (EAW) in the tension range between 20 and $100 \mathrm{hPa}^{1,10}$ and the air capacity (Air) are marked in the Figure3. All other required water and air capacities (different kind of cultivation) can be calculated based on these functions. The hydraulic functions demonstrate the special performance of horticultural substrates for horticultural applications. The natural soils are even worse and were far from achieving the threshold value of $10 \%$. The rewetting properties of most substrates were sufficient with the exception of three substrates which exceeded the threshold value for the water drop penetration time of 5 seconds. ${ }^{17}$ Also the shrinkage showed a great variability and ranged between 0.4 and 9.1 vol.- $\%$ within the substrates. Only about half of the samples achieved or exceeded the threshold value for the capillary rise of $30 \mathrm{~cm}$ height for a $5 \mathrm{mmd}^{-1}$ rate. Same situation could be observed for the mineral sandy (Ls3) and clayey loam (Lts).

\section{Rating framework}

The hydraulic rating framework of horticultural substrates consists of two parts: the rating of the basic soil hydrological properties and the rating of the limitations. The easily plant-available water (EAW) and air capacity (Air) are basic properties and are assessed on a 5-point scale (1-very good, 2- good, 3- medium, 4- satisfactory, 5- non 
satisfactory), and capillary rise (CR) on a 2-point scale. The best score of the basic properties (EAW, Air, CR) is 5, and the poorest rating is

1. The limitations (water drop penetration time and soil shrinkage) are assessed in a 3-point scale. The score of the limitations ranges between 0 (no limitation) and 2 (strong limitation). Only the score of the most severe limitation is considered. In the case of score 2 for the strong rewetting limitation and score 1 for the shrinkage the value 2 has to be considered. The total rating for the evaluation of the hydraulic performance of the substrates in horticulture is calculated as the sum of the basic score minus the score of the dominating limitation. The highest score is 12 , the lowest is 1 .

2. The hydraulic properties of 36 commercially available horticultural substrates were measured. Taking into account the evaluation scales developed by Schindler $\mathrm{U}^{4}$ the suitability of the substrates was evaluated for cultivation in containers and in the bed Figure 3.

We could not find substrates which were evaluated as satisfactory or non-satisfactory for horticultural use. Most sensitive and limiting were the air capacity in shallow containers and the shrinkage and rewetting behaviour. More than the half of the substrates was evaluated as good and very good. However, there were some differences between cultivation in the field or bed. More detailed information is given in. ${ }^{5}$

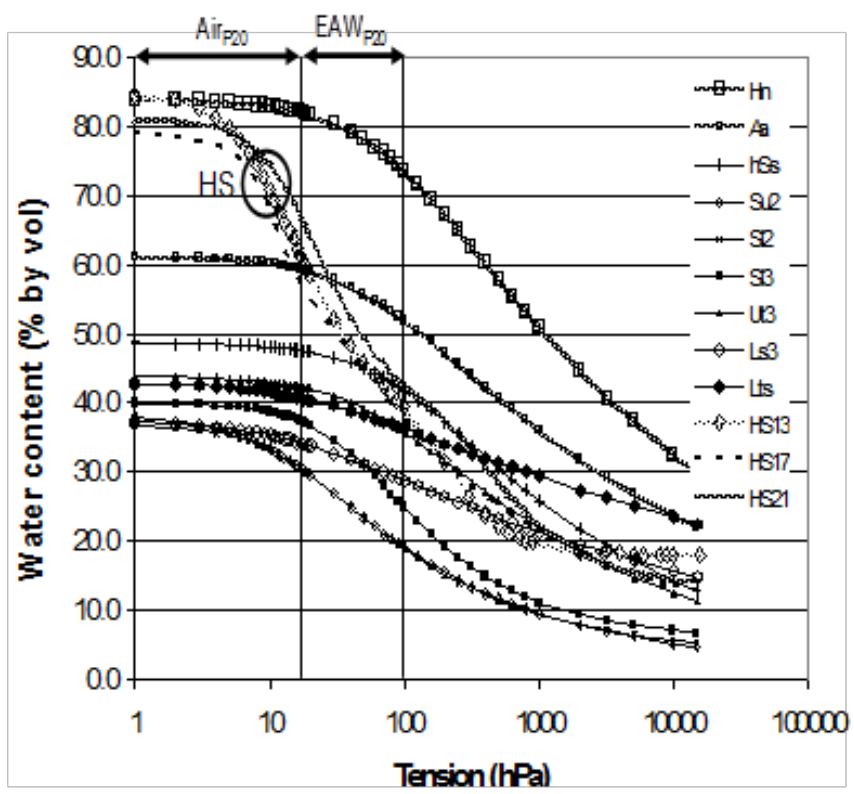

Figure 3 Water retention curves of the natural mineral and organic soils and exemplarily of three horticultural substrates (HS), AirP $\mathrm{P}_{20}$ average air volume in $20 \mathrm{~cm}$ high containers, $\mathrm{EAWP}_{20}$ - easily plant available water in $20 \mathrm{~cm}$ high containers.

\section{Conclusion}

1. The applied hydraulic measurement techniques and methods (EEM, HYPROP, WDPT) proved to be suitable to characterize the hydraulic properties of horticultural substrates as a basis for evaluating their hydraulic applicability for horticultural use.

2. The results of the especially composed horticultural substrates in this study showed their superiority for horticultural applications compared with natural soils.

3. The hydraulic performance of totally peat-free substrates was not worse than those containing peat.
4. Generally, the water demand in containers was sufficiently covered by most samples.

5. The most sensitive element of horticultural substrates was the air supply, especially for cultivation in shallow containers. High water penetration times and substrate shrinkage is of main relevance for sustainable, resource-saving water and nutrient management.

6. The proposed evaluation framework provides an opportunity to compare the hydraulic properties of the substrates taking into account threshold values for the plant water and air supply.

\section{Acknowledgements}

None.

\section{Conflict of interest}

Author declares that there is no conflict of interest.

\section{References}

1. Raviv M, Lieth JH. Soilless culture: Theory and practice. Elsevier. 2007;608.

2. Caron J, Pepin S, Periard Y. Physics of growing media in green future. Proc. IS on Growing Media \& Soilless Cultivation. Acta Hort. 2014;1034:309318.

3. Schindler U, Müller L. Hydraulic Performance of Horticultural Substrates-2. Development of an Evaluation Framework. Horticultuae. 2017;3(1):6.

4. Schindler U, Müller L, Eulenstein F. Hydraulic Performance of Horticultural Substrates-1. Method for Measuring the Hydraulic Quality Indicators. Horticultuae. 2017a;3(1):5.

5. Schindler U, Lischeid G, Müller L. Hydraulic Performance of Horticultural Substrates- 3. Impact of Substrate Composition and Ingredients. Horticultuae. 2017b;3(1):7.

6. Schindler U, Durner W, von Unold G, et al. The evaporation methodExtending the measurement range of soil hydraulic properties using the airentry pressure of the ceramic cup. J Plant Nutr Soil Sci. 2010;173(4):563572 .

7. Hallett PD. An introduction to soil water repellency. Proceedings of the 8 th International Symposium on Adjuvants for Agrochemicals. Christchurch. New Zealand: ISAA3 2007.

8. Von Post L. Sveriges Geologiska Undersöknings torvinventering och nogra av des hittils vunna resultat (SGU peat inventory and some preliminary results). Svenska Mosskulturforeningens Tidskrift. Jonköping. 1922;36:137.

9. DIN EN 13041. Bodenverbesserungsmittel und KultursubstrateBestimmung der physikalischen Eigenschaften- Rohdichte (trocken), Luftkapazität, Wasserkapazität, Schrumpfungswert, und Gesamtporenvolumen, Beuth Verlag GmbH, Berlin: 2012.

10. Verdonck O, Gabriels RI. Reference method for the determination of physicalproperties of plant substrates. II. Reference method for the determination of chemical properties of plant substrates. Acta Hort. 1992;302:169-179.

11. UMS Gmb, H Munich. HYPROP(-Laboratory evaporation method for the determination of pF-curves and unsaturated conductivity, 2011.

12. Schindler U, Doerner J, Müller L. Simplified method for quantifying the hydraulic properties of shrinking soils. J Plant Nutr Soil Sci. 2015;178(1):136-145.

13. Fields JS. Soilless Substrate Hydrology and Subsequent Impacts on PlantWater Relations of Containerized Crops. Virginia Tech; 2016. 
14. Schindler U, Müller L, Da Veiga M, et al. Comparison of water-retention functions obtained from the extended evaporation method and the standard methods sand/kaolin boxes and pressure plate extractor. J Plant Nutr Soil Sci. 2012;174(4):527-534

15. Schelle H, Heise L, Jänicke K, et al. Water retention characteristics of soils over the whole moisture range-comparison of laboratory methods. Europ J Soil Sci. 2013;64(6):814-821.
16. Schelle H, Iden SC, Peters A, et al. Analysis of the agreement of soil hydraulic properties obtained from multistep-outflow and evaporation methods. Vadose Zone Journal. 2010;9(4):1080-1091.

17. Blanco Canqui H, Lal R. Extent of soil water repellency under long-term no-till soils. Geoderma. 2009;149(1-2):171-180. 